\section{Poverty and terrorism}

\section{Siddharta Mitra}

$\mathrm{F}$ ollowing the terror attacks in the United States on 11 September 2001, prominent world leaders called for an eradication of poverty so that terrorism could be brought to an end - so did, for example, U.N. Secretary General Kofi Annan, WTO head Michael Moore, and U.S. President George W. Bush at a development summit in Mexico in March 2002. This presumed link between poverty and terrorism (or lack of education and terrorism) was questioned by social scientists such as Alan Krueger, James Piazza, Alberto Abadie, and Claude Berrebi who concluded that it did not stand up to empirical scrutiny. ${ }^{1}$ In contrast, this article argues that it is the academics who may have been wrong and that, therefore, the jury should still be out on this issue. Through case studies it is argued that when poverty is accompanied by certain enabling factors, terrorism might indeed arise and flourish.

The article is structured as

After the 9/11 attacks on the United

States, world leaders identified poverty

as a cause of terrorism. A number of academics have questioned the presumed link between poverty and terrorism. This article argues that it is the academics who may be wrong. follows. First, a critique of the approach taken by social scientists to the study of the link between poverty and terrorism is offered. Second, an alternative framework to study the potential link is provided. Third, a case study of Northeastern India demonstrates that in the regions of Mizoram, Tripura, and Assam poverty and perceived economic exploitation are among the causes of terrorism there. Fourth, terrorism in Latin America shows that in these cases, too, poverty, hardships, and persisting inequalities are among the motivating forces.

Critique

A complex phenomenon, terrorism is determined by the interaction of a milieu of social, economic, and political factors. They consist of necessary factors (such as the presence of a powerful leader and adequate finances), facilitating factors (such as unemployment among youth), precipitating factors (such as communal differences, economic exploitation, intensification of poverty, or unemployment), and perpetuating factors (e.g., suitable geographical terrain, policies of appeasement). Terrorism can arise in many ways and there is hardly any one single factor that serves as a sufficient condition. For instance, if a country is poor but there is an absence of suitable leadership to lead potential terrorists and give vent to discontentment then terrorism will not happen. Only when sufficient factors are present and included in the data set would a typical method of empirical study, regression analysis, be appropriate.

For example, a widely cited article by A. Krueger and J. Maleckova argues that poverty being a major reason for terrorism is inconsistent with the fact that Palestinian suicide bombers and other Middle Eastern terrorists mostly do not stem from poor families. But surely one has to acknowledge that poverty is more appropriately conceived as a cause of terrorism in the macro sense than in the micro sense: if a welloff person sees his race or people being exploited or rendered impoverished then he or she, too, might join the ranks of terrorists. (Or, as economists put it, terrorism can owe its genesis to the interdependence of utility functions.) But this is not formally recognized in Krueger's and Maleckova's study. Similarly, the selection mechanism used to choose people for suicide bombing mission is biased toward the selection of educated and relatively affluent people. In an earlier piece, Krueger and Maleckova themselves point out that education and affluence can signal that a person is interested in becoming a suicide bomber because of reasons other than narrow individual or household gain. A higher level of education and greater affluence is treated as a signal of greater commitment and ability. The final selection of suicide bombers, on which the empirical studies are based, does not tell us about the characteristics of the pool of willing people from which the selection is made. It follows that the statistical conclusions drawn from such studies may be incorrect.

One scholar, James Piazza, gives examples of rich countries that served as apparent breeding grounds for terrorism, and of poor countries that did not. ${ }^{2}$ For example, Saudi Arabia is associated with terrorism even though in terms of average income levels it is in fact a rich country. Yet, although not poor in an absolute sense, its riches are of fairly recent origin, and even these were subject to considerable volatility and uncertainty as in the two decades before the post-9/11 oil-price boom, Saudi Arabia experienced a significant negative average growth rate of GDP per capita. Still, the pinch of poverty some may have experienced in Saudi Arabia is of a different quality than that experienced in a country that has been poor continuously Absolute and relative poverty, or perceptions thereof, thus might differently contribute to the wish to lash out by means of terror. People in some country or region within a country might compare their continuing poverty with the rising affluence of neighbors and/or consider themselves to be victims of exploitation as, for example, as in the case of the Northeast Indian state of Assam discussed later on.

The role of education itself is misunderstood. Contrary to Krueger and Maleckova, it is not especially surprising to find that educated people play a disproportionately prominent role as terrorists in the Middle East - perhaps due, in part, to the greater relative decline of their income as compared to that of their less educated counterparts - nor does this phenomenon imply that ignorance, illiteracy, or discontentment are not significant factors in terrorism: after all, lack of literacy and other forms of deprivation might raise the hackles of educated and uneducated people alike. (Indeed, the case studies presented later on argue that poverty and economic discontent have been partly responsible for the rise of terrorism in Northeastern India and Latin 
America.) But as pointed out earlier, more educated people possess greater ability at organization and at undertaking complex tasks which therefore makes them more likely to successfully engage in terrorism. Of course, this does not imply that a more literate country will take recourse to terrorism more readily.

An alternative framework

It is difficult to treat terrorism in the same way as most economic phenomena that are amenable to statistical (econometric) analysis. For example, an increase in a country's investment rate will in most cases increase its rate of economic growth. This can be traced in that the presence of relevant influences on growth other than the investment rate can be controlled for mathematically. In contrast, the presence of a sufficiently high level of poverty may not stimulate terrorism if intermediary, facilitating factors needed to "convert" poverty into terror are absent. Correlating poverty and terror without explicitly accounting for, measuring, and entering these facilitating factors into the data analysis will lead to misleading statistical results when the linkage between the two main variables of interest - poverty and terror - hinge crucially on these factors. But such independence has been assumed in virtually all studies on this subject to date so that it is not possible to tease out the relationship between poverty and terrorism effectively. In fact, scholars have not yet developed a complete list of facilitating and precipitating factors, nor have they been able to either pinpoint or develop a consensus on their interaction in generating terrorism. These factors might be so numerous that controlling for the incidence of all of them might reduce the socalled degrees of freedom in statistical estimation to such an extent that credibility of the results is jeopardized. Moreover, some of these factors are qualitative and subjective so as to render objective measurement more difficult.

For an act of terror to occur, certain necessary conditions must all be fulfilled such as the presence of a powerful leader and adequate finances to purchase weaponry and inputs such as bombs, guns, and remote controls. If necessary conditions are fulfilled then, in addition, at least one precipitating factor is needed for terrorism to occur (see Figure 1). This could be poverty, ignorance, acute unemployment, lack of political freedom, perceived racial, linguistic, or religious discrimination, colonial exploitation, a "war" of cultures caused by globalization, etc. Given the satisfaction of all necessary conditions and the attainment of a critical magnitude of at least one of the precipitating variables, the chances of terrorism occurring are enhanced by the presence of certain catalytic or facilitating factors. Totalism, which refers to the capacity to see oneself as "completely good" and another side as "completely evil," is a powerful facilitating phenomenon. ${ }^{3}$ Totalistic ideas are generally propagated by a terrorist leader. Unemployment among youth, an age group characterized by immense energy and unformed and malleable ideals, might serve to facilitate recruitment for a terrorist movement. Mystical manipulation, which refers to the distortion of religious teachings to support a terrorist cause, may be another medium through which terrorism can operate, and the powerful personality of a leader may enhance the effect of mystical manipulation. Linguistic or physical barriers between two groups of people can be used by the leader of one group to spread misinformation about the other group. Poverty, ignorance, and unemployment can also act as catalysts for terrorism because of the hopelessness that they tend to generate. These serve as examples of facilitating and precipitating factors. Some scholars emphasize the role of globalizing technologies as facilitators of terrorism. Thus, information technology has reduced the cost of coordinating terrorism and increased the cost of tracing the source of such coordination and organization. ${ }^{4}$ High inequality in education (highly educated leaders followed by uneducated or illiterate followers) helps leaders to manipulate followers and command blind obedience. The generally poor educational status of women in developing countries might also be a facilitator as the presence of educated women generally has a sobering and soothing effect, reduces violence, strengthens civil society, and reduces birth rates. ${ }^{5}$

Although the presence of necessary, precipitating, and facilitating factors might lead to terrorist incidents, there must also exist perpetuating factors if terror is to be sustained or prolonged. For example, unless active measures are used to promote dissension and facilitate exit, leaving a terrorist group can be difficult. Another source of perpetuation is that totalism may beget totalism, and when two groups view each other totalistically, a vicious cycle of mutual terror may result. Outright repression of one group by another might also perpetuate terrorism.

Given these causes, mechanism that can generate terrorism are quite obvious. The general framework is presented in Figure 1. If all necessary factors are present (e.g., leadership, finance) then any one of the precipitating causes (e.g., poverty) acting in conjunction with one or more of the facilitating causes (e.g., totalistic views) might lead to acts of terror. If perpetuating causes are absent then terrorism will die down after an initial burst. However, when perpetuating factors persist, a location or region or nation might be caught in a vicious cycle of terrorist activity. ${ }^{6}$

\section{Northeastern India: backwardness as a stepping stone to terrorism}

This section briefly examines the cases of three provinces in Northeastern India, Mizoram, Assam (or Asom), and Tripura, with information about terrorist activities 
and their causes drawn from the work of Sanjoy Hazarika. ${ }^{7}$ Northeastern India has been characterized by slow economic growth and poor development of infrastructure. Consequently, the gap between the these regions and the rest of India has been increasing. The first case is that of Mizoram, a hilly region that was only lightly administered by the British. Every fifty years its bamboo forests are covered in flowers. This, however, marks the arrival of a sad period, known as the mautam, as the flowers attract millions of rats that destroy crops. The mautam of 1959, for example, caused an enormous incidence of hunger and starvation. Appealing for help to the state government of Assam, in which the Mizo-inhabited region lay, and receiving no adequate response, Mizos formed famine fighting squads under the leadership of Laldenga, a young bank clerk who did not himself feel the pinch of the famine as much as did the general population.

Dreaming of a strong and vibrant nation for his people, Laldenga reorganized the famine fighting squads into the Mizo Famine Front. He developed a network of workers and supporters who traveled to the remotest villages with food and a message criticizing the negligence displayed by the Assam state government and the Mizo District Council (the official Mizo political forum). The message said that the Mizos deserved a nation of their own, separate from India. Eventually the Mizo Famine Front was renamed as the Mizo National Front (MNF), with independence as its goal. Executing acts of terrorism from 1966 onward, MNF overran many government establishments such as police stations and the state Treasury in Aizawl, the Mizo district headquarters. The state retaliated through the Indian army until peace was finally brokered in 1987, with Laldenga becoming the Chief Minister of Mizoram. The case shows that deprivation can provide the fuel required for terrorist action. The scarcity generated during the mautam spurred the formation of the famine fighting squads which evolved into a terrorist organization.

The second northeast Indian case is that of the United Liberation Front of Asom (ULFA). This organization took shape in 1979. Some of its key figures were Motoks, members of communities with links to the Ahom rulers of Assam. During colonial times, and virtually without compensation, the British dispossessed the Motoks of the land they owned in the Dibrugarh-Tinsukia sector of Assam and converted it into sprawling tea estates. Deprived of large tracts of land, and denied their previous relatively affluent way of life, Motoks felt exploited, and this sense of exploitation continued for a hundred years climaxing in the formation of the ULFA. Without going into details here, suffice it to say that ULFA held sway in the late 1980 s and early 1990s through extortion and murder, particularly of noted businessmen. The rise of the ULFA illustrates how poverty and relative deprivation can push members of a community into terrorist activity.

Terrorism in Tripura, the third northeast Indian case, was the outcome of deprivation on an even larger scale. In 1947, 93 percent of Tripura's population was made up of indigenous people. Attacks on Hindus in East Pakistan (now Bangladesh) led many refugees to settle in Tripura. By 1981 the total population of the state was
2.06 million, but now only 28.5 percent were indigenous. Immigrants seized economic and political influence. The sense of deprivation among the indigenous people of Tripura led to the formation of the Tripura Volunteer Force (TVF) in 1980 led by Bijoy Hrangkhawl. Pent-up anger and frustration saw expression in many bloody incidents. The most infamous of these was the massacre at Mandai Bazaar where hundreds of Tripuris and members of other tribal communities descended on unsuspecting Bengalis and slaughtered them. After much violence, the TVF signed a peace accord with the Indian government in 1988. As for ULFA, the case of TVF was born out of deprivation and dispossession of the indigenous people.

It is fairly easy to identify and classify the factors leading to terrorism in Northeastern India according to the framework discussed earlier. In all cases, an important role (a "necessary factor") was played by the leaders - Laldenga in the case of MNF, Bijoy Hrangkhawl in the case of TVF, and Arabinda Rajkhowa, Anup Chetia, and Pradip Gogoi, the founders of ULFA. Another necessary factor, adequate finances, was unproblematic as the states in which these terrorist groups operated were flanked by neighboring countries with which India's relationships were not always cordial. In fact, Hazarika explicitly recounts how ULFA and other terrorist organizations were helped by ISI, the Pakistani secret service agency. In terms of precipitating factors, all three cases revolve around deprivation reaching a saturation point. While in the case of Mizoram it was absolute deprivation, with people going hungry, and the lack of response from the government that led to the terrorist movement, in Assam and Tripura natives took to terrorism after being increasingly deprived of what they considered to be rightfully theirs. Facilitating factors also were similar across the cases: all are adjoining states that had (and have) much in common in terms of culture and history. All were aided by the mountainous, forested geographic terrain, coupled with poor infrastructure. Strong tribal loyalties, a high literacy rate, and climbing unemployment rates were also strong facilitating factors. As to perpetuating factors, the mechanism of "totalism begets totalism" certainly played a role in prolonging terrorist activity: natives paid back allegedly cruel activities of the Indian army in the same coin.

Latin America: terrorism from poverty, inequality, and empathy

The link between poverty and terrorism is not peculiar to Southeast Asia (or Northeas India). Instead a generalization may well be made: given the fulfillment of certain conditions, poverty can lead to terrorism. For illustration, examine a few Latin America cases. Instead of looking at specific regions, this section examines the role and influence of poverty and inequity in terrorist ideologies of groups that operate(d) in Latin America. ${ }^{8}$

Considering their average per capita income, the countries studied here are characterized by extreme inequality and poverty. In 1994, as many as 60 percent of Colombia's population lived at below a dollar a day, the international poverty line 
defined by the World Bank, even as by 2005, Colombia's per capita income (measured in PPP\$) rose to $\$ 7,304 .^{9}$ For comparison, India's 2005 income was $\$ 3,452$, with poverty rates, for the same year, around 35 to 40 percent. And Colombia's Gini coefficient, a measure of inequality, was a very high 0.586 (out of a maximum of 1.0) in 2003 as compared to 0.325 for India in $1999 / 2000 .{ }^{10}$ Brazil had a per capita income (PPP\$) of \$8,402 in 2005, a relatively low poverty rate of 17 percent in 1998 but a Gini coefficient of 0.58 in 2003, reflecting socially unacceptable inequality levels. Mexico's per capita income (PPP\$) was $\$ 10,751$ in 2005, but the poverty rate was 37.3 percent in 1997, and the Gini coefficient stood at 0.473 in 2005, again reflecting very high inequality. Bolivia's per capita income (PPP\$) of $\$ 2,819$ in 2005 was much lower than that of even India. The poverty rate did not seem very high at 22 percent in 2003 , but its Gini coefficient was very high at $0.601-$ the picture of a country where a sizeable minority is poor, the majority is fractionally above the poverty line, and a small minority controls most of the wealth. Ecuador, likewise, is characterized by high inequality and high poverty.

Now consider terror activities in Colombia, Brazil, Mexico, Bolivia, and Ecuador. Colombia's National Liberal Army (ELN in its Spanish acronym) was influenced by Fidel Castro's and Che Guevera's early theories and actions. It consisted of urban leftwing intellectuals who claimed to represent the interests of the poor, demonstrating that poverty can motivate the nonpoor to engage in terrorist acts. With its violent terrorism campaign, another Colombian terrorist group, Movimiento 19 (M19), also professed support for the poor. It was established when former dictator-cum-populist Rojas Pinilla, who enjoyed wide support from the urban poor, lost the Colombian presidential election of 1970. The group dissolved in 1990 under the pressure of Colombian government security forces.

In Brazil, the Popular Revolutionary Vanguard (VPR) developed when a leftleaning head of state was removed by the military and replaced by a right-wing regime. VPR consisted of radical students and ex-soldiers. Driven by communist ideology, it considered capitalists, multinationals, and oligarchs as its main enemies. With the recovery of the Brazilian economy in the 1970 s, the popular base for the VPR eroded and it gradually folded up. Bolivia's National Liberation Army was formed by Che Guevera in late 1966 as an offshoot of the Cuban revolution. Reacting to the country's inequities, the aim of this group was to overthrow the regime and form a communist state. Another Bolivian terrorist group, the Zarate Willka Armed Forces of Liberation, was a reaction against the Christian, Mormon, and American influence that had allegedly marginalized Bolivian Indians socially and economically. Their two basic goals were to "fight for the rights of the poor" and "fight against U.S. intervention in Bolivia." The Zarate Willka Armed Forces of Liberation have been inactive since 1989.

Mexico's Revolutionary W orker Clandestine Union of the People Party (RWCUP) formed in the late 1960 s or early 1970 s. The (self-stated) goal of this terror group, which followed a Marxist Leninist ideology, was the "liberation of Mexico from the bourgeoisie and North American imperialism." It engaged in robberies, assassinations, kidnappings, and small-scale bombings and targeted multinationals and capitalist establishments. In 1994 it merged with the Popular Revolutionary Army of Mexico. Finally, in Ecuador the Group of Popular Combatants is an active terrorist group with a communist foundation. Their protests are directed against imperialist government policies and against Ecuadorian oligarchs, again showing the proclaimed goal of fighting for the interests of the deprived or poor.

These cases suggest that poverty and inequality were and are among the driving forces behind terrorist activity in Latin America. And the data show that people in the case study countries indeed suffer from high levels of poverty and inequality. Thus, poverty, deprivation, and inequality emerge as determinants of terrorist activity.

\section{Conclusion}

The Northeast Indian and Latin America cases discussed in this article demonstrate that terrorist activity can be motivated by the interests of the poor. That poverty per se does not emerge as a statistically significant determinant of terrorism in econometric analyses merely says that counterexamples exist: not all cases of poverty need lead to terrorism. But this does not refute that causation can flow from poverty to terror. Rather, it just points to the possibility that necessary conditions and facilitating factors to "translate" motive to action may have not been present in a particular case.

The argument made here must not be misconstrued as offering a simple option for the eradication of terror: either end poverty or prevent terror's preconditions from being satisfied. After all, terror can be motivated for reasons unrelated to poverty. But even if related to poverty, favorable companion factors, be they cultural, geographical, or accidental in nature, can take on a life of their own and are not always suitable for policy manipulation anyway. Still, buttressed by the case studies drawn from Latin America and Northeastern India and contrary to the academic opinions referred to at the outset of this article, poverty alleviation does remain an important tool for undermining at least some terrorist activity.

Notes

Siddharta Mitra is Research Director, Consumer Unity Trust Society (CUTS) International in Jaipur, India. He may be reached at sm2@cuts.org. The views expressed are those of the author and should not be attributed to CUTS.

1. Krueger (2002; 2003), Kueger and Maleckova (2003); Piazza (2006), Abadie (2004), Berrebi (2007).

2. Piazza (2006). 
3. See Barrie-Anthony (n/d) for a discussion of totalism.

4. Crenshaw (2005); Krug and Reinmoller (2003).

5. Scully (n/d).

6. Also see Mitra (2005).

7. Hazarika (1994).

8. This information is available from MIPT's Terrorism Knowledge Base, now merged into the Global Terrorism Database (see http://www.start.umd.edu/data/gtd/) [accessed 6 May 2008].

9. PPP\$, or international dollars, adjust average incomes for purchasing power or cost of living differences across countries.

10. Data on poverty ratios and per capita incomes from World Bank (various years). Figures for Gini coefficients are based on U.N. estimates.

\section{References}

Abadie, A. 2004. "Poverty, Political Freedom and the Roots of Terrorism.” Working Paper W 10859. Boston: National Bureau of Economic Research.

Barrie-Anthony, S. n/d. "Totalism - The Terrorist's Mindset." See http://www.causes-of-terrorism.net/totalism.htm [accessed 19 May 2008].

Berrebi, C. 2007. "Evidence About the Link between Education, Poverty and Terrorism among Palestinians." Peace Economics, Peace Science and Public Policy, Vol. 13, Issue 1, Article 2.

Hazarika, S. 1994. Strangers of the Mist: Tales of War and Peace from India's Northeast. New Delhi: Penguin Books.

Krueger, A.B. and J. Maleckova. 2002. "The Economics and the Education of Suicide Bombers." The New Republic. http://www.alanalexandroff.com/nr-krueger.pdf.

Krueger, A.B. and J. Maleckova. 2003. "Education, Poverty and Terrorism: Is There a Causal Connection?" Journal of Economic Perspectives, Vol. 17, No. 4, pp. $119-144$.

Krueger, A.B. 2003. "Poverty Prevention Doesn't Create Terrorists." The New York Times. 29 May.

Mitra, S. 2005. "A Framework for Analytical Treatment of Terrorist Problems." http://ssrn.com/abstract=777086 [accessed 19 Feb. 2008].

[MIPT] The Memorial Institute for the Prevention of Terrorism. n/d. Terrorism Knowledge Base. www.tkb.org [accessed 20 Feb. 2008].
Piazza, J.A. 2006. "Rooted in Poverty? Terrorism, Poor Economic Development and Social Cleavages," Terrorism and Political Violence, 18:1, pp. 159-177.

Scully, L. n/d. "The Importance of Educating Girls and Women." See http://www.girlsed.org/resources/The_Importance_of_Educating_Girls_and_W omen.htm [accessed 19 May 2008].

World Bank. Various years. World Development Indicators. Washington, D.C: World Bank. 